Research Article

\title{
An Overview of Information and Communication Technology Tools Application in Healthcare System
}

\author{
Dineshkumar B',$\underline{\text { K Krishnakumar }}$, Smitha KNair ${ }^{3}$, David Paul ${ }^{4}$ \\ ${ }^{1,2,3,4}$ Department of Pharmaceutics, St. James College of Pharmaceutical Sciences, St. James Hospital Trust Pharmaceutical \\ Research Centre (DSIR Recognized), Chalakudy, Kerala.
}

DOI: https://doi.org/ 10.24321/2394.6539.201903

\section{I $\quad \mathbf{N} \quad \mathbf{F} \quad \mathbf{O}$}

\section{Corresponding Author:}

Dineshkumar B, Department of Pharmaceutics, St. James College of Pharmaceutical Sciences, St. James Hospital Trust Pharmaceutical Research Centre (DSIR Recognized), Chalakudy, Kerala.

E-mail Id:

dinsbiotech@gmail.com

Orcid Id:

https://orcid.org/0000-0002-9207-6242

How to cite this article:

Dineshkumar B, Krishnakumar K, Nair SK, Paul D. An Overview of Information and Communication Technology Tools Application in Healthcare System. J Adv Res Med Sci Tech 2019; 6(1\&2): 15-17.

Date of Submission: 2019-12-13

Date of Acceptance: 2020-01-03

\section{$\begin{array}{llllllll}\mathbf{A} & \mathbf{B} & \mathbf{S} & \mathbf{T} & \mathbf{R} & \mathbf{A} & \mathbf{C} & \mathbf{T}\end{array}$}

\begin{abstract}
Information and Communication Technology (ICT) are improving the health care services throughout the world. In health care system, ICT involve application of information and communication processing using computer for storage, recovery, sharing and use of knowledge on uses of medicines and patient-centred services. Similarly, web-based system, e-prescription, automated dispensing system, mobile technology and innovations in ICT tools are giving a way to access the data in health care sector all over the world. In healthcare system, ICTs can enhance the qualities of services to dispense the medicines and to maintain the data on patients medication history and patients safety. With this information, this review article mainly focused on overview of ICT tools application in healthcare system.
\end{abstract}

Keywords: ICT, Healthcare, Application

\section{Introduction}

The Information and Communication Technology (ICT) have been used widely in healthcare system of developed countries with more advances. ICT provides chances for individuals and health professionals to get information as well as communicate with other healthcare professionals in an easy manner. ${ }^{1}$

\section{Benefits if ICT in Health Care System}

- ICT can be used for the storage of structured patient records in the hospital. Further, ICT can allow the electronic prescribing, dispensing and administration of drugs in the hospital.
- ICT can automate the handling of medicines. ICT provides idea to monitor the efficacy and safety of drugs.

- ICT can improve patient safety. Health professionals can give quality care on patients' safety and drug efficacy.

- ICT helps to health professionals to access the patient record systems for professional decision-making in providing patient-centred services.

\section{Internet and Web-based Platforms}

The internet has been used by health professional for easy communications. Now, the usage of internet by health professionals has been increased in order to display and distribute information on drug and patient safety. ${ }^{2}$ 


\section{E-Prescribing}

E-Prescribing is growing rapidly and showing significant benefits for patients and physicians. In U.S. now allows e-prescribing, including e-prescribing of controlled substances. E-prescribing is showing following key-benefits: ${ }^{3}$

- It helps to prevent prescription drug errors.

- It gives idea on Automated clinical decision support.

- Collect the patient's medication history.

- Identify the use requirements for electronic prescriptions.

- Collect the patient fulfilment of prescriptions.

\section{Automated Dispensing System}

Robotic dispensing systems can count tablets, label the prescription vial, store the number of medications in the pharmacy. It can give the patient information to ensure accuracy. Robots Dispensing systems are being used in community pharmacy in some of UK hospital. This robot's system has ability to handle high volumes of dispensing of medicines in community pharmacy and to release pharmacists to develop and deliver patient-centred services. The robotic automated dispensing system having following advantages such as reducing dispensing. errors, improving the efficiency of dispensing process, optimizing the use of space in the hospital pharmacy departments. ${ }^{4}$

\section{Use of Mobile Technology in Health Care}

Mobile technology gives opportunities for health professionals in order to improve and assess medication adherence in patients. Use of mobile technology in health care system provides following benefits such as helps to ensure the medication dosages, patients can easily manage their own medications, better communication with health professionals on prescription updates, improved patient health through medication adherence. ${ }^{5}$

\section{ICT-Tools in Medical Education}

ALEX (Advanced Learning Exchange) - ICT Tool: It is an online medical education system.

\section{Learning Activities}

Waves: Using ALEX-ICT tool, the students can identify wave properties such as crest, trough, wavelength, amplitude, and frequency. It can give idea on relationship between frequency, amplitude, and wavelength. It can provide idea to create a model of a wave.

Kahoot - ICT Tool: The student can able to solve equations and inequalities with addition, subtraction, multiplication, and division.

Name That-nym - ICT Tool: The students can able to understand the words by relating them to opposites (antonyms) and to words with similar but not identical meanings (synonyms). ${ }^{6}$
Voki: It is a fun tool that students can use to complete their classwork, assignments or projects in the class room or home. ${ }^{7}$

WISE-MD (Web-based Initiative in Surgical Education) ICT Tool: This WISE-MD tool is used to give a computerized linear description of the patient and the patient-physician interaction from the first visit of patient, diagnostic process, laboratory studies and finally to the postoperative visits. ${ }^{8,9}$

BioDigital Human - ICT Tool: The BioDigital Human is a 3D platform that gives easy understanding of human anatomy and disease conditions to the health professionals. Benefit of this tool is to use online Human Studio models and save models in your account, share with others health professionals. ${ }^{10}$

\section{Conclusion}

ICTs involve information and communication processing using various software. This Software play an important role in storage, accessibility, sharing the information by health care professionals. Management and administration use this latest ICTs tools in the field of health care system to provide better services to dispensing of medicines and patient's safety. Internet and availability of ICTs facilities also an important, to provide information to health care professionals, patients, and stake holders.

\section{Conflict of Interest: None}

\section{References}

1. Jawla S, Rai DV. Improvement in health care services using information and communication technologies (ICTs) by community pharmacy. International Journal of Growth and Development 2018; 2: 1-4. Available from: https://webcache.googleusercontent. com/search?q=cache:rMCL_umhPWIJ:https:// updatepublishing.com/journal/index.php/ijgd/article/ download/5417/4876+\&cd=1\&hl=en\&ct=clnk\&gl=in.

2. Ganan D, Caballe S, Clariso R, Conesa J et al. ICT-FLAG: a web-based e-assessment platform featuring learning analytics and gamification. International Journal of Web Information Systems 2017; 13: 25-54. [Google Scholar/ ResearchGate].

3. Benefits of E-Prescribing 13 ways physicians (and patients) benefit from electronic prescribing. Available from: https://www.drfirst.com/benefits-ofe-prescribing/. Accessed on 20 October 2019.

4. Rodriguez-Gonzalez CG, Herranz-Alonso A, EscuderoVilaplana $V$ et al. Robotic dispensing improves patient safety, inventory management, and staff satisfaction in an outpatient hospital pharmacy. J Eval Clin Pract 2019; 25(1): 28-35. Available from: https://onlinelibrary.wiley. com/doi/pdf/10.1111/jep.13014 [PubMed/ Google Scholar].

5. What is the Impact of Mobile Technology on Medication 
Adherence? Available from: https://blog.avella.com/ impact-mobile-technology-medication-adherence. Last accessed on 25 October 2019.

6. BioDigital Human. Available from: https://chrome. google.com/webstore/detail/biodigitalhuman/ meefjekipolcgabfgaclcpdkbghhmoah?hl=en. Last accessed on 27 October 2019.

7. Information \& Communication Technology in Health Education. Available from: https://infocusrx.com/blog/ information-communication-technology-in-healtheducation. Last accessed on 27 October 2019.

8. Szyld D, Uquillas K, Green BR, Yavner SD, Song H, Nick $\mathrm{MW}$ et al. Improving the clinical skills performance of graduating medical students using "WISE on Call," a multimedia educational module. Simul Healthcare 2017; 12(6): 385-392. [PubMed/ Google Scholar].

9. Hale JF, Terrien JM, Quirk M, Sullivan K, Cahan M. The impact of deliberate reflection with WISE-MD ${ }^{\mathrm{TM}}$ modules on surgical clerkship students' critical thinking: a prospective, randomized controlled pilot study. Advances in Medical Education and Practice 2018; 9: 757-766. [PubMed/ Google Scholar].

10. BioDigital - Powering the World's Understanding of the Human Body. Available from: https://www.biodigital. com/3d-human-studio. Last accessed on 28 October 2019. 